\title{
Hetero Diels-Alder Adduct Formation between Nitrosobenzene and Tetra-methyl Purpurogallin and its retro-Diels-Alder Reaction
}

\author{
Daniela Gamenara ${ }^{a}$, Eduardo Días $^{a}$, Néstor Tancredi ${ }^{a},{ }$ Horacio Heinzen ${ }^{a}$, \\ Patrick Moyna ${ }^{a, b}$ * and Eric J. Forbes
}

\author{
${ }^{\mathrm{a}}$ Facultad de Química, Universidad de la República, Avda. General Flores 2124, Montevideo, Uruguay \\ ${ }^{\mathrm{b}}$ Chemistry Department, University of Birmingham, Birmingham, Edgbaston B15 2TT, Great Britain
}

\begin{abstract}
É descrita uma síntese eficiente de um aduto de Diels-Alder da tetrametilpurpurogalina (TMPG) e o nitrosobenzeno (NOB). A cinética da decomposição térmica do aduto, que segue um mecanismo de retro-Diels-Alder foi estudada usando espectroscopía de ${ }^{1} \mathrm{H}-\mathrm{RMN}$.
\end{abstract}

\begin{abstract}
An efficient synthesis of a Diels-Alder adduct between purpurogallin tetramethyl ether (TMPG) and nitrosobenzene (NOB) is reported. The thermal decomposition kinetics of the adduct, which follows a retro-Diels-Alder mechanism, was studied using ${ }^{1} \mathrm{H}-\mathrm{NMR}$ spectroscopy.
\end{abstract}

Keywords: Hetero Diels-Alder, tetra-methyl purpurogallin, nitrosobenzene

\section{Introduction}

The renewed interest in both natural and semisynthetic endoperoxides and NO-containing products, both of which present interesting medicinal applications ${ }^{1-5}$, led us to reconsider the preparation of these structures through DielsAlder reactions. Heteroatomic functional arrangements can result in dienophiles which react to produce heterocyclic Diels-Alder adducts ${ }^{6,7}$. Some di-heteroatomic systems, such as $\mathrm{O}=\mathrm{O}, \mathrm{O}=\mathrm{N}$ and $\mathrm{N}=\mathrm{N}$, also show this behavior, with the formation of di-heteroatomic cyclic structures $6,8-11$. Nitroso compounds, in particular, are known to give oxazine type adducts ${ }^{12-15}$.

Adequately substituted tropolones and benzotropolones behave as dienes in Diels-Alder reactions, both with homoand heteroaromatic (Figure 1. I from TMPG and II from eucarvone) dienophiles $8,9,10,14$.

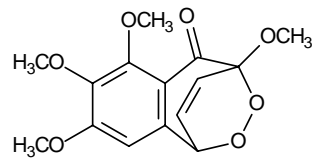

(I)

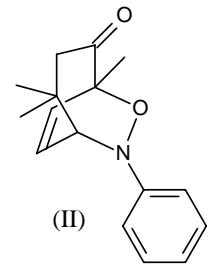

Figure 1.
Peroxo TMPG (I) is thermally unstable, and breakage of the peroxide bond results in a rearranged product ${ }^{8,9}$. In the case of $\mathrm{NO}$ bond the thermal behavior is different, giving way to a facile retro Diels-Alder reaction with quantitative recovery of both diene and dienophile. Adducts from thebaine acting as diene and nitrosoarenes as dienophiles show different degrees of dissociation, depending on the electronic characteristics of the substituents placed para- to the nitroso group in the nitrosoarenes ${ }^{15}$.

We here describe the preparation of the tetramethyl purpurogallin and nitrosobenzene Diels-Alder adduct, together with the determination of the rates of the retroDiels-Alder reaction.

\section{Results and Discussion}

The adduct was obtained both in polar (methanol, diethyl ether) and non-polar solvents (dichloromethane, toluene, hexane). In polar solvents the reaction was not complete giving rise to mixtures of unreacted starting products and the adduct. Using hexane the adduct could be isolated in good yields and purified.

The structure of the TMPG-NOB Diels-Alder adduct (Figure 2) was characterized by ${ }^{1} \mathrm{H}$ NMR, ${ }^{13} \mathrm{C}$ NMR and confirmed by X-Ray diffractometry ${ }^{16}$. Of the two possible orientations of the N-O bridge, only III was observed.

The thermal decomposition of the adduct proceeds through a retro-Diels-Alder mechanism as it is shown by

*e-mail : pmoyna@bilbo.edu.uy 
<smiles></smiles><smiles>O=Nc1ccccc1</smiles>
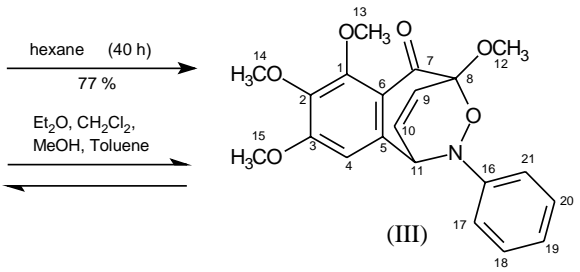

Figure 2.

${ }^{1} \mathrm{H}$ NMR experiments, in which the coexistence of the three compounds involved in the reaction could be detected at the equilibrium point. When using an initial adduct concentration of $10 \mathrm{mg} / \mathrm{mL}$ the dissociation of the adduct was $60 \%$ at $30^{\circ} \mathrm{C}, 78 \%$ at $40^{\circ} \mathrm{C}$ and $86 \%$ at $50^{\circ} \mathrm{C}$.

To establish the kinetic parameters for the retro-DielsAlder we studied the intensity variations in the ${ }^{1} \mathrm{HNMR}$ signals for specific protons (H-9 and H-9'), both of the adduct and starting materials. The experiments were carried out in $\mathrm{CDCl}_{3}$ solution at $30^{\circ}$ and $50^{\circ}$ with an initial adduct concentration (Ci) of $10 \mathrm{mg} / \mathrm{mL}$, and at $40^{\circ} \mathrm{C}$ with $(\mathrm{Ci})=5,10$, and $15 \mathrm{~mL}$.

Kinetic law at $40^{\circ} \mathrm{C}$ and direct rate constant $\left(\mathrm{k}_{1}\right)$ were determined using the differential method, studying the system at the start of the reaction ${ }^{17}$.

Table 1.

\begin{tabular}{cc}
\hline $\begin{array}{c}\text { Adduct initial } \\
\text { concentration }(\mathrm{Ci})\left(\mathrm{mol} \mathrm{L}^{-1}\right)\end{array}$ & $\begin{array}{c}\text { Initial rate }(\mathrm{Vo}) \\
\left(\mathrm{mol} \mathrm{L}^{-1} \mathrm{~min}^{-1}\right)\end{array}$ \\
\hline $1.3055 \times 10^{-2}$ & 0.0001 \\
$2.611 \times 10^{-2}$ & 0.0002 \\
$3.916 \times 10^{-2}$ & 0.0003 \\
\hline
\end{tabular}

Reaction order $=\alpha=1 ; \mathrm{R}^{2}=1$

$$
\left.\mathrm{V}_{0}=\mathrm{k}_{1} \text { [Adduct }\right]
$$

Constants were obtained from the equilibrium concentrations (eq. [1]), and the inverse rate constant $\mathrm{k}_{-1}$ was established by combining equations (1) and (2).

$\mathrm{Keq}=[\mathrm{TMPG}][\mathrm{NOB}] /[\mathrm{TMPG}-\mathrm{NOB}]$

$\mathrm{Keq}=\mathrm{k}_{1} / \mathrm{k}_{-1}$

The values for $\Delta \mathrm{G}^{\mathrm{o}}, \Delta \mathrm{H}^{\mathrm{o}}$ and $\Delta \mathrm{S}^{\mathrm{o}}$ were obtained from equations (3) and (4) ${ }^{18}$.

$\Delta \mathrm{G}^{\mathrm{o}}=-\mathrm{RT} \ln \mathrm{Keq}$

$$
\begin{aligned}
& \Delta \mathrm{G}^{\mathrm{o}}=\Delta \mathrm{H}^{\mathrm{o}}-\mathrm{T} \Delta \mathrm{S}^{\mathrm{o}} \\
& \Delta \mathrm{H}^{\mathrm{o}}=13.7 \mathrm{~K} \mathrm{~J} \text { mol L} \\
& \\
& \quad \text { Activation energy }\left(\mathrm{R} \mathrm{R}^{2}=0.9972\right. \text { was calculated using } \\
& \text { Arrhenius equation: }
\end{aligned}
$$

$$
\begin{gathered}
\mathrm{k}_{1}=\mathrm{A} \mathrm{e}^{-\mathrm{Ea} / \mathrm{RT}} \\
\mathrm{Ea}=23.6 \mathrm{~K} \mathrm{~J} \mathrm{~mol} \mathrm{~L}{ }^{-1} ; \mathrm{R}^{2}=0.9999
\end{gathered}
$$

\section{Conclusions}

The Diels-Alder reaction of TMPG and NOB in hexane resulted in the formation of the TMPG-NOB adduct as a crystalline solid. The structure could be established by spectroscopic methods and X-ray diffraction.

The kinetic and thermodynamic characteristics of the decomposition reaction at three temperatures were studied. Rate law, rate constant of the direct and inverse reaction at $40^{\circ} \mathrm{C}$ and the activation energy of the reaction were determined. The concentration of each species in equilibrium was established by observation of the ${ }^{1} \mathrm{H}$ NMR signals for specific protons.

The equilibrium in the retro-Diels-Alder reaction of TMPG-NOB was characterized by the determination of the thermodynamic constants $\Delta \mathrm{G}^{\circ}, \Delta \mathrm{H}^{\circ}$ and $\Delta \mathrm{S}^{\circ}$. The $\Delta \mathrm{G}^{\circ}$ value of approximately $2 \mathrm{kcal} / \mathrm{mol}$ is low, which is borne out by the facile formation and decomposition of the adduct where the direction of the reaction controlled simply by displacing the product from solution or eliminating one of the reactants from the mixture. The $\Delta \mathrm{H}^{\circ}$ value for the reaction (approximately $14 \mathrm{kcal} / \mathrm{mol}$ ) indicates that while the adduct is stable once formed, it can be decomposed with a small energy outlay, for both of the liberated moities recover their condition of free aromatic systems. While there is a strict control of the orientation of the reactants leading to the adduct, $\Delta \mathrm{S}^{\circ}$ is not influenced by temperature.

Table 2.

\begin{tabular}{cccccc}
\hline $\mathrm{T}\left({ }^{\circ} \mathrm{C}\right)$ & $\mathrm{Keq}\left(\mathrm{mol} \mathrm{L}^{-1}\right)$ & $\mathrm{k}_{1}\left(\mathrm{~min}^{-1}\right) ; \mathrm{R}^{2}$ & $\mathrm{k}_{-1}\left(\mathrm{~mol} \mathrm{~L}^{-1} \mathrm{~min}^{-1}\right)$ & $\Delta \mathrm{G}^{\mathrm{o}}\left(\mathrm{KJ} \mathrm{mol}^{-1}\right)$ & $\Delta \mathrm{S}^{\mathrm{o}}($ u.e. $)$ \\
\hline 30 & $2.28 \times 10^{-2}$ & $2.4 \times 10^{-3} 0.9878$ & $1.05 \times 10^{-1}$ & 2.3 & 37.6 \\
40 & $5.02 \times 10^{-2}$ & $8.2 \times 10^{-3} 0.9992$ & $1.63 \times 10^{-1}$ & 1.9 & 37.7 \\
50 & $9.29 \times 10^{-2}$ & $2.7 \times 10^{-3} 0.9983$ & $2.93 \times 10^{-1}$ & 1.5 & 37.6 \\
\hline
\end{tabular}


These results indicate that there is the possibility of modulating the rates of the Diels-Alder and retro-DielsAlder reactions by controlling the aromaticity of starting materials. A series of compounds and derivatives capable of liberating NO containing moieties has been planned to further study their stability, decomposition patterns and pharmacological properties.

\section{Experimental}

\section{General}

NMR Spectra were measured in a Bruker Avance 400 DPX.

Kinetic studies were measured by ${ }^{1} \mathrm{H}$ NMR at $400 \mathrm{MHz}$ using $\mathrm{CDCl}_{3}$ (Aldrich $99.8 \%$ pure) as solvent.

IR spectra were measured in a FT-IR DR-8031 Shimadzu spectrophotometer in $\mathrm{KBr}$ pellets.

UV spectra were measured in a Unicam SP 800 ultraviolet spectrophotometer.

MS were measured in a Shimadzu GC-MS QP 1100 EX. Sample ionization was carried out by electron impact (20 and $70 \mathrm{eV}$ ).

Solvents were distilled in glass prior to use.

\section{Nitrosobenzene}

Nitrosobenzene (m.p. $68^{\circ} \mathrm{C}$ ) was prepared immediately prior to use following Vogel ${ }^{19}$.

\section{Purpurogallin}

Purpurogallin (m.p. 265-267 decomp.) was prepared following Barltrop ${ }^{19}$.

\section{Tri-O-methyl purpurogallin}

An aqueous solution of sodium hydroxide ( $28 \mathrm{~g}, 0.70$ mol in $200 \mathrm{~mL}$ ) was added to a mixture of purpurogallin (45 g, $0.20 \mathrm{~mol})$, crushed ice (100 g) and dimethylsulfate $(60 \mathrm{~mL})$ with continuous stirring. The mixture was stirred overnight. The solid precipitate was collected, washed with water and recrystallized from ethanol to yield tri-Omethyl purpurogallin $\left(24 \mathrm{~g}, 45 \% \text {, m.p. } 169-171^{\circ} \mathrm{C}\right)^{20}$. ${ }^{1} \mathrm{H}-\mathrm{NMR}\left(\mathrm{CDCl}_{3}\right): \delta 7.17$ (d, $J 11.2 \mathrm{~Hz}, \mathrm{H}-11$ '), 6.67 (s, H-4'), 6.67 (dd, $J 9.3$ and 11.2 Hz, H-10'), 6.60 (d, $J 9.3$ $\mathrm{Hz}, \mathrm{H}-9$ '). ${ }^{13} \mathrm{C}-\mathrm{RMN}\left(\mathrm{CDCl}_{3}\right): \delta 186.34,159.77,158.67$, 157.28, 137.62, 136.52, 134.82, 123.96, 112.74, 106.07, 61.11, 56.99, 56.49. MS (IE; $\left.70 \mathrm{eV}, 25^{\circ} \mathrm{C}\right) \mathrm{m} / \mathrm{z} 262(100$ $\%), 247$ (30\%), 233 (22\%), 219 (32\%), 201 (15\%), $191(19 \%), 173(19 \%), 147$ (15\%), $131(9 \%), 105(23$ $\%), 89(13 \%), 77(14 \%), 63(11 \%), 51(13 \%)$.

\section{Tetra-O-methyl purpurogallin}

Tri-O-methyl purpurogallin ( $5 \mathrm{~g}, 0.02 \mathrm{~mol})$ and aqueous potassium hydroxide $(32.5 \mathrm{~g}, 0.58 \mathrm{~mol}$ in $50 \mathrm{~mL})$ were shaken until an homogeneous mixture was obtained. Dimethylsulfate $(10 \mathrm{~mL})$ was added in one portion, and the mixture warmed over a free flame until a reaction ensued. The flame was then removed, and after the first violent reaction had subsided, the mixture was boiled for a further 30 minutes. The reaction mixture was cooled to room temperature, the solid collected and washed with water. The solid was then dried and extracted with a large volume or diethyl ether. The ether extract was dried $\left(\mathrm{MgSO}_{4}\right)$, and the solvent removed to yield tetra-O-methyl purpurogallin $\left(45 \mathrm{~g}, 86 \%\right.$, m.p. $\left.87-88^{\circ} \mathrm{C}\right)$. Recrystallization from methanol yields the pure compound, m.p. $92-93^{\circ} \mathrm{C}^{20}$. IR $(\mathrm{KBr}): v_{\max } / \mathrm{cm}^{-1}=2943.7,1647.4,1620.4,1587.6$, 1572.2, 1529.7, 1489.2, 1466.1, 1450.0, 1394.7, 1350.3, 1279.0, 1252.0, 1215.3, 1178.6, 1095.7, 1043.6, 1014.7, 981.9, 951.5, 870.0, 808.3, 787.1, 771.6, 748.5, 719.5, 648.2. ${ }^{1} \mathrm{H}-\mathrm{NMR}\left(\mathrm{CDCl}_{3}\right): \delta 6.90(\mathrm{~d} J 11.7 \mathrm{~Hz}, \mathrm{H}-11$ ') 6.75 (s, H-4'), 6.51 (dd, $J 11.7$ and 8.7 Hz, H-10'), 6.15 (d $J \quad 8.7 \mathrm{~Hz}, \mathrm{H}-9$ '). ${ }^{13} \mathrm{C}-\mathrm{RMN}\left(\mathrm{CDCl}_{3}\right): \delta$ 185.11, 159.21, $155.57,153.34,143.95,133.06,129.27,126.01,123.69$, $107.17,105.25,62.95,61.37,56.36,56.35$. MS (IE; 70 $\left.\mathrm{eV}, 25^{\circ} \mathrm{C}\right): \mathrm{m} / \mathrm{z} 276(100 \%), 261(19 \%), 248(29 \%), 244$ (31\%), 233 (22\%), 218 (62\%), 205 (20\%), 190 (16\%), $173(13 \%), 161$ (15\%), 147 (13\%), 131 (21\%), 119 (17 $\%), 115(13 \%), 89(12 \%), 76(17 \%)$.

\section{Tetra-O-methyl purpurogallin-nitrosobenzene adduct}

Tetra- $O$-methyl purpurogallin $(1.11 \mathrm{~g}, 4.02 \mathrm{mmol})$ and nitrosobenzene $(0.52 \mathrm{~g}, 4.9 \mathrm{mmol})$ were dissolved in hexane $(50 \mathrm{~mL})$. The solution was left standing at room temperature, in the absence of light, for 40 hours. The white crystals obtained were filtered and recrystallized from methanol to yield tetra-O-methyl purpurogallin-nitrosobenzene adduct (1.18 g, $77 \%)$, m.p. $114-115^{\circ} \mathrm{C}$. The filtrate was concentrated under vacuum and a further crop of crystals was obtained and recrystalized from methanol (160 mg, 10 \%). IR (KBr): $v_{\max } / \mathrm{cm}^{-1} \quad 3003.5,2982.3,2943.7,1693.7$, 1589.5, 1491.2, 1456.4, 1402.4, 1356.1, 1325.3, 1282.8, $1257.7,1215.3,1197.9,1134.3,1107.3,1088.0,1049.4$, 1032.0, 987.7, 954.9, 918.2, 898.9, 877.7, 841.1, 806.3, 763.9, 694.5, 655.9. ${ }^{1} \mathrm{H}-\mathrm{NMR}\left(\mathrm{CDCl}_{3}\right): \delta 7.21(\mathrm{dd}, J 7.8$ and $7.3 \mathrm{~Hz}, \mathrm{H}-18$ and H-20), 7.09 (d, J 7.8 Hz, H-17 and H21), 6.93 (d, J 7.3 Hz, H-19), 6.62 (s, H-4), 6.55 (dd, $J 9.2$ and $6.7 \mathrm{~Hz}, \mathrm{H}-10), 6.12$ (d, J 9.2 Hz, H-9), 5.18 (d, J 6.7 Hz, H-11), 3.87 (s, H-12), 3.84 (s, H-13), 3.79 (s, H-14), 3.63 (s, H-15). ${ }^{13} \mathrm{C}-\mathrm{NMR}\left(\mathrm{CDCl}_{3}\right): \delta 190.2$, (7); 157.9, (3); 156.7, (1); 150.9, (16); 144.2, (2); 136.7, (10); 135.8, (5); 
129.3, (18, 20); 127.7, (9); 123.4, 19); 120.5, (6); 118.3, $(17,21) ; 109.4,(4) ; 102.7,(8) ; 69.5,(11) ; 62.2,(13) ; 61.4$, (14); 56.6, (15); 53.3, (12). MS (IE; $\left.70 \mathrm{eV}, 25^{\circ} \mathrm{C}\right): \mathrm{m} / \mathrm{z}=276$ (83\%), 261 (17\%), 248 (32\%), 233 (24\%), 218 (65\%) $205(20 \%), 190(15 \%), 173(11 \%), 161(14 \%), 147(9 \%)$, 131 (7\%), $115(10 \%), 107$ (62\%), 77 (100\%), 51 (52\%). Found: C: $65.8 \%$; H: $5.8 \%$; N: $3.7 \%$; Requires: C: $65.8 \%$; H: $5.5 \%$; N $3.7 \%$. IR vmax $\left(\mathrm{CH}_{2} \mathrm{Cl}_{2}\right) 1696,1586 \mathrm{~cm}^{-1}$; vmax (nujol) $1700,1585 \mathrm{~cm}^{-1}$. UV $\lambda \max$ (methanol) 245 , $296 \mathrm{~nm}(\varepsilon=26,500$ and 10,500 , respectively).

\section{Acknowledgements}

The authors acknowledge the financial support of the CSIC (Comisión Sectorial de Investigación Científica, Project $N^{\circ} 195$ ) and of the PEDECIBA Programme (student scholarship to DG). PM remembers with gratitude the encouragement of the late Prof. Maurice Stacey FRS, and acknowledges the support of the British Council through a students scholarship (1965-1968). Thanks are due to the Micro Analytical service of the Chemistry Department (Univ. Birmingham) and to Dr. G. Moyna (USIP) for helpful suggestions.

\section{References}

1. Woerdenbag, H. J.; Pras, N.; Van Uden, W.; Wallaart, T. E.; Beekmann, A. C.; Lugt, C. B. Pharm. World Sci. 1994, 16, 169.

2. Phillipson, J. D.; O’ Neill, M. J. In: Biological Active Natural Products. Hostettmann, K.; Lea, P. J. Eds.;
Oxford Science Publ.; Oxford, England, 1987.

3. Mukherjee, T. Fitoterapia 1991, 62, 197.

4. Al-Sa'doni, H.; Ferro, A. S. Clin. Sci 2000, 98, 507.

5. Saavedra, J.; Keefer, L. Chem. Britain 2000, 36, 30.

6. Boger, D. L.; Weinreb, S. M. Hetero Diels-Alder methodology in Organic Synthesis. Academic Press; San Diego, 1987.

7. Weinreb, S. M. Acc. Chem. Res. 1985, 18, 16.

8. Forbes, E. J.; Griffiths, J. J. Chem. Soc. C 1967, 601.

9. Forbes, E. J.; Griffiths, J. J. Chem. Soc. C 1968, 572.

10. Forbes, E. J.; Griffiths, J. J. Chem. Soc. C 1968, 575.

11. Boyd, D.; Dorrity, M.; Hand, M.; Malone, J.; Shama, N.; Dalton, H.; Gray, D.; Sheldrake, G. J. Amer. Chem. Soc. 1991, 113, 666.

12. Scholz, S.; Marschall-Weyerstahl, H.; Weyerstahl, P. Liebigs Ann. Chem. 1985, 10, 1935.

13. Streith, J.; Defoin, A. Synthesis, 1994, 1107.

14. Hart, H.; Sambharamadon, K. R.; Willer, R. J. J. Org. Chem. 1979, 44, 1.

15. Kirby, G. W.; Bentley, K. W.; Horsewood, P.; Singh, S. J. Chem. Soc. Perkin I 1979, 3064.

16. Mariezcurrena, R.; Heinzen, H.; Gamenara, D.; Moyna, P.; Mombru, A. Acta Cryst. (submitted for publication).

17. Carey, F. A.; Sundberg, R. J. Advanced Organic Chemistry. $3^{\text {rd }}$ Ed.; Plenum Press; New York, 1993.

18. Castellan, G. Physical Chemistry. $3^{\text {rd }}$ Ed.; AddisonWesley; New York, 1983.

19. Vogel, A. I. Practical Organic Chemistry. 4th Ed.; Longman; London, 1948, p. 603.

20. Barltrop, J. A.; Nichols, J. S. J. Chem. Soc. 1948, 116.

Received: September 5, 2000 Published on the web: April 25, 2001 